\title{
MEASUREMENT OF RADIO WAVE VELOCITIES IN THE FIRN ZONES OF POLAR ICE SHEETS (Abstract only)
}

\author{
by
}

\author{
Sion Shabtaie and Charles R. Bentley
}

(Geophysical and Polar Research Center, University of Wisconsin, Madison, Wisconsin 53706, U.S.A.)

ABSTRACT

A common-reflection point profiling experiment to obtain electromagnetic wave velocities in the ice at Dome $\mathrm{C}$ at $35 \mathrm{MHz}$ was carried out to a maximum antenna separation of $2 \mathrm{~km}$. Four different recording systems were used for this experiment. The echoes from numerous internal reflecting horizons within the ice and the bedrock were recorded in four different ways: in A-display form on film using an oscilloscope, in intensity-modulated form using the Honeywell Visicorder and thermal intensifier on heat-sensitive silver paper, and in both raw and signal-averaged form on magnetic tape.

Travel times of oblique reflections from nearly 160 internal layers down to a depth of $2600 \mathrm{~m}$ and reflections from the ice bottom were measured at each station along the profile. The average wave velocities from the surface of each internal 1ayer were measured to obtain a continuous mean velocity vs depth profile.

Velocity-density models derived from the dielectric mixture equations of Looyenga, Böttcher, Lichtenrecker, Hanai-Bruggeman and Wiener were compared against the measurements. In addition Robin's empirical relationship was also used in this study. The preliminary results show that the observed velocitydepth profile for the ice column is compatible with
Wiener's equation (with Formzahl $=0$ ) and a newly derived empirical relationship (from this study) of

$$
\varepsilon=\varepsilon_{i}\left[\frac{\gamma_{f}}{\gamma_{i}}\right]^{1.5}
$$

where $\gamma_{i}$ is ice density, $\gamma_{f}$ firn density, $\varepsilon$ dielectric constant of mixture, and $E_{i}$ dielectric constant of ice; $\gamma_{\mathrm{f}}>0.55 \mathrm{~kg} \mathrm{~m}^{-3}$. It appears that the electromagnetic wave velocity in the firn is $20 \mathrm{~m} \mu \mathrm{s}^{-1}$ or more, which is higher than previously assumed.

The above models were also compared with velocity measurements in the Devon Island bore holes (Robin 1975) and at several sites on the Ross Ice Shelf where the ice is relatively thin compared to Dome $C$ so that the effect of firn on mean velocities is more pronounced. The results for these sites suggest again that Wiener's equation and empirical relationship from this study produce velocities compatible with the observed values.

\section{REFERENCE}

Robin G de Q 1975 Velocity of radio waves in ice by means of a bore-hole interferometric technique. Jourmal of Glaciology 15(73): 151-159

\section{DEEP GEOELECTRIC AND RADAR SOUNDINGS AT DOME C, EAST ANTARCTICA (Abstract only)}

by

Sion Shabtaie,

(Geophysical and Polar Research Center, University of Wisconsin, Madison, Wisconsin 53706, U.S.A.)

\section{Franz Thyssen}

(Institut für Geophysik der Westfälischen Wilhelms-Universität, Corrensstrasse 24,

D-4400 Münster, West Germany)

and Charles R. Bentley

(Geophysical and Polar Research Center, University of Wisconsin, Madison, Wisconsin 53706, U.S.A.)

ABSTRACT

Deep geoelectric soundings using a Schlumberger array were carried out at Dome C, Antarctica. To penetrate the $3500 \mathrm{~m}$ thick ice, electrode halfspacings up to $8 \mathrm{~km}$ (the largest yet made on polar ice) were used. A constant-current dc transmitter with voltages up to $10 \mathrm{kV}$, resulting in constant currents of up to $10 \mathrm{~mA}$, was employed; potentials were measured with an electrometer and recorded continuously on an $x-y$ recorder.

A computer program has been developed to calculate apparent resistivities on an ice sheet in which the density, temperature, and impurities, and thus the actual resistivity, vary continuously with depth. Preliminary models show that the actual resistivity at a depth of about $500 \mathrm{~m}$ increases downward by a factor of about three, and that elevated resistivities must persist to much greater depth. This change in resistivity appears to be linked to transition from ice-age to Holocene ice.

The cause of this resistivity increase is not well understood, and may be attributed to any of several physical and chemical changes that also occur at about the same depth. 